\title{
Enhanced desalination performance of capacitive deionization using ZIF-8/Graphene nanocomposite electrode
}

\author{
Z. Kamali $^{1}$ - M. Khashehchi ${ }^{1}$ (D) P. Zarafshan ${ }^{1} \cdot$ E. Pipelzadeh $^{2}$
}

Received: 2 November 2019 / Accepted: 28 October 2020 / Published online: 12 November 2020

(c) The Author(s) 2020

\begin{abstract}
Capacitive deionization (CDI) is greatly recommended as a desalination process for its eco-friendly and low energy consuming technique in removing salt ions $(\mathrm{NaCl})$ from salty water. This study reports a Zeolitic Imidazolate Framework-8/ Graphene (ZIF-8/G) nanocomposite modified electrode performance in CDI technology. Based on its promising features, like large surface area and good electric conductivity, graphene is an adequate electrode. Interestingly, ZIF- 8 is homogeneously well intergrown on the surface of graphene. Hence, electrochemical performance such as electrical conductivity and cyclic voltammetry in CDI unit were examined, and characteristics like the morphology, identification and determining the structure of the prepared materials were investigated by scanning electron microscopy (SEM), X-ray diffraction (XRD), Fourier Transform Infrared Spectroscopy (FT-IR). As an adsorbent, the prepared ZIF-8/G nanocomposite exhibits the best adsorption capacity about $141.6037 \mathrm{~F} / \mathrm{g}$ higher than each individually and great electrical conductivity about $672 \mu \mathrm{s} / \mathrm{cm}$. The high adsorption specific capacity and good reusability of the ZIF-8/G nanocomposite suggests that it can be applied as novel adsorbents showing attractive potential for the CDI technique.
\end{abstract}

Keywords ZIF-8/Graphene $\cdot$ Nanocomposite $\cdot$ Capacitive deionization $\cdot$ Water desalination

\section{Introduction}

Presently, the crisis of water scarcity has not only intensified in the field of domestic consumption, but it has also affected the agricultural and industrial sectors which make up the bulk of the consumption. The challenge of providing sufficient and fresh water would be more problematical in case of population growth, industrialization, and soil contamination which will affect the available fresh water resources $(\mathrm{Li}$ et al. 2010a, b; Pendergast and Hoek 2011; Wang et al. 2007; Zou et al. 2008; Elimelech and Phillip 2011). These important causes, along with social reasons such as public health, individual health, safety, and the environment, have provided a great impetus for the development of modern technologies to water shortages (Elimelech and William 2011). As a result, a solution such as water desalination has emerged as a key

M. Khashehchi

m.khashehchi@ut.ac.ir

1 Department of Agro-Technology Engineering, College of Aburaihan, University of Tehran, Tehran, Iran

2 Chemistry Engineering Department, University of Queensland, Brisbane, QLD, Australia structure for our future life. In fact, desalination is defined as a process that removes dissolved solids from the brackish water or seawater, which are the most two important resources of useless waters.

Accordingly, there have been many efforts to improve the desalination techniques. Since $97.5 \%$ of all the Earth's water is contained within the oceans as saltwater, desalination in most countries is the best choice to provide fresh water among all of the possible approaches. It does not surprise us to be told that most traditional desalination technologies are energy consuming, expensive and need hard maintenance (Al-Shammiri and Safar 1999; Pilat 2001; Tanaka et al. 2000; El-Sayed 1996; Kim and Choi 2010; Farmer et al. 1996; Yasin et al. 2016). Currently, Electro-Dialysis (ED), ion-exchange, distillation, Reverse Osmosis (RO), thermal methods like Multi-Stage Flash (MSF) and many other techniques play as different approaches for desalination (Elimelech and William 2011). Despite many efforts, researchers are still looking for effective methods with the lowest energy loss and the highest efficiency.

Capacitive deionization (CDI) is an electrochemical research field, with primary applications in brackish water desalination and wastewater purification. It is well known for 
being less expensive, energy consuming, and it requires less pump pressure. A CDI cell usually contains two extendedarea electrodes that are electronically isolated by a separator, and saltwater is pumped through the area between two electrodes. The electrodes are charged when a power supply (a low voltage) is connected to the electrodes. This potential causes charged ions in the water to migrate to oppositely charged electrodes and to be electrostatically contained in electric double layers within the electrode surface (Mirzadeh et al. 2014; Rica et al. 2012). The certain amount of specific surface area and specific capacity may lead to significant salt adsorption on electrode (Fig. 1). This process forms the charge half-cycle and is also the desalination step. Once the electrodes are fully charged, the electrodes can be discharged by short-circuiting, allowing the stored ions to be released into the main flow, resulting a waste brine stream.

As stated, electrodes are the most essential part of designing this desalination system. Although the shape and the flow arrangement between the electrodes have been considered in a wide variety of researches (Jeon et al. 2013; Lee et al. 2014; Gao et al. 2015; Srimuk et al. 2016; Suss et al. 2012; Cohen et al. 2011; Johnson and Newman 1971; Porada et al. 2013; Park et al. 2007), the influential features like conductivity, high specific area, porosity, chemical stability, and also cost issues should be considered for designing a new electrode's material. So far, there have been a number of carbon-based materials applied on the CDI cell, involving Carbon Black (CBs) (Park et al. 2007), Mesoporous Carbons (MCs) (Zhai et al. 2011), Activated Carbons (ACs) (AlMarzooqi et al. 2014), Carbon Aerogels (CAs) (Landon et al. 2012), Carbon Nanotubes (CNTs) (Presser et al. 2011), Carbide-Derived Carbons (CDCs) (Porada et al. 2012), etc.

Recently, carbon-based materials are showing up in the research environment. Graphene is a carbon material with a huge theoretical specific surface area of $2600 \mathrm{~m}^{2} / \mathrm{g}$ at room temperature (Stoller et al. 2008). These intriguing properties enabled graphene to be a promising potential for a graphenebased material for CDI electrode (Wang et al. 2012). However, the application performance of graphene is restricted

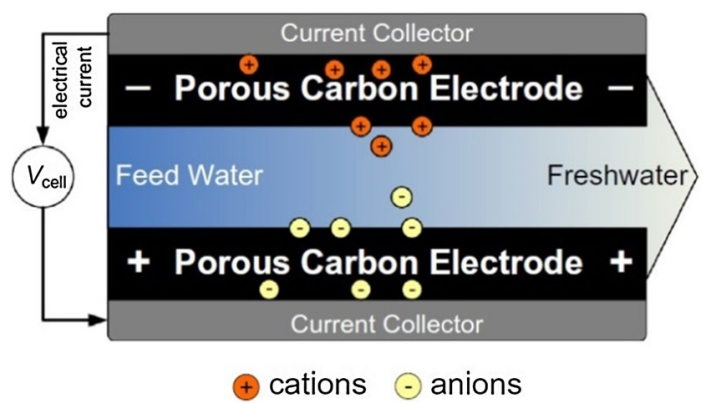

Fig. 1 Schematic design of a cell for Capacitive Deionization (Mirzadeh et al. 2014) because the graphene usually tended to take part in van der Waals interactions ( $\mathrm{Li}$ et al. 2008). To turn this around, it should compose with some molecules or polymers that are qualified for sitting on the surface of graphene layers, such as Metal-Organic Frameworks (MOFs) (Yang et al. 2015). MOFs are inorganic metal connectors and organic linkers. They are better candidates for combinations, with enjoyment of features such as large surface areas, high porosity, great mechanical stability, and ordered crystalline structures, compared to the other porous materials (i.e., silica's and active carbons). Zeolitic Imidazolate Frameworks (ZIFs) are a subclass of metal-organic frameworks and promising porous materials. They are linked by imidazole or imidazolate bridging ligands. ZIFs materials and their nanocomposites are very effective to remove organic and inorganic hazardous materials. Josephine et al. in 2010 used ZIF-8 as a membrane for gas separations like $\mathrm{CO}_{2}, \mathrm{H}_{2}, \mathrm{C}_{3} \mathrm{H}_{8}, \mathrm{CH}_{4}, \mathrm{~N}_{2}$, and $\mathrm{O}_{2}$ (Ordonez et al. 2010). Thereafter, various researchers found the capability of ZIF-8 in gas separation. Utilizing ZIF-8 and its composites in aqueous solutions started in 2016 by Duan et al., for water desalination (Duan et al. 2016). Also, Gao et al. (2018) prepared nanoporous carbons with ZIF-8 as a template and activation agent for supercapacitors, which is another usage for energy saving. Following the work of Kumar et al. (2013), the concept of compositing ZIF-8 and graphene oxide, along with various improvements on its properties, has been leading to extensive researches in this field (Pokhrel et al. 2018). Zhou et al. used GO/ZIF-8 for storing $\mathrm{H}_{2}$ at $298 \mathrm{~K}$ (Zhou et al. 2015). Li et al. also used ZIF-8/G for energy saving in super-capacitors ( $\mathrm{Li}$ et al. 2014). Despite the crucial influence of the composites, there have been less reports of working on salt removal in CDI. A recent report has used the nanocomposite for removing sodium chloride $(\mathrm{NaCl})$ from water. Accordingly, the nanocomposite has been calcinated at $950{ }^{\circ} \mathrm{C}$ which resulted $136 \mathrm{~F} / \mathrm{g}$ (Wang et al. 2017).

In this study, a ZIF-8/G nanocomposite is synthesized successfully with ZIF-8 nanoparticles sited on threedimensional (3D) graphene sheet. The nanocomposite was studied with a combination of experimental techniques including X-ray Photoelectron, FT-IR, TGA, and electron microscopy (SEM). The nanocomposite greatly improves the surface area and finally the specific capacity of the ZIF-8/G nanocomposite and showed a reliable stability. Herein, the advantage of ZIF-8/G nanocomposite electrode was used in $\mathrm{NaCl}$ from brackish water. ZIF-8/G nanocomposite after it's synthesizing and carbonization at $800{ }^{\circ} \mathrm{C}$ (which is an optimum temperature according to its thermal analysis) was put on an ultrathin carbon sheet as a pair of ZIF-8/G modified electrodes in a glassy cell in the CDI system. Finally, the electrical conductivity and the specific capacitive showed the progress. 


\section{Experiment}

\section{Materials}

Natural flake graphite nanoparticles (less than $100 \mathrm{~nm}$ in size), potassium permanganate $\left(\mathrm{KMnO}_{4}\right)$, sulfuric acid $\left(\mathrm{H}_{2} \mathrm{SO}_{4}, 95-97 \%\right)$, hydrochloric acid $(\mathrm{HCl}, 37 \%)$, hydrogen peroxide $\left(\mathrm{H}_{2} \mathrm{O}_{2}, 30 \%\right)$, and potassium hydroxide were purchased from Merck. Ethyl alcohol $\left(\mathrm{C}_{2} \mathrm{H}_{5} \mathrm{OH}, 99.7 \%\right)$ was purchased from Hamoon Teb-e Markazi Co. All the chemicals were used as-received, and no further treatment has been done on.

\section{Preparation of graphene oxide}

Graphene oxide was synthesized and prepared from natural graphite via modified Hummer's method. Five gram of graphite flacks, $2.5 \mathrm{~g}$ of sodium nitrate $\left(\mathrm{NaNO}_{3}\right)$ and $160 \mathrm{ml}$ of sulfuric acid $\left(\mathrm{H}_{2} \mathrm{SO}_{4}\right)$ were mixed together in a container with a capacity of $500 \mathrm{ml}$. Then, the mixture was stirred for 30 min within an ice bath at $4{ }^{\circ} \mathrm{C}$ (avoiding exposure). Eighteen gram of potassium permanganate $\left(\mathrm{KMnO}_{4}\right)$ was added to the solution little by little with vigorous stirring in $500 \mathrm{rpm}$. The stirring was kept going over a night (about $15 \mathrm{~h}$ ). Then, $150 \mathrm{ml}$ of deionized water was added while the solution is stirring at $35^{\circ} \mathrm{C}$.

After a vigorous stirring, $50 \mathrm{ml}$ of $\mathrm{H}_{2} \mathrm{O}_{2}(30 \%)$ was added and promptly the golden particles appeared in a black solution. The mixture was washed a couple of times by adding $5 \% \mathrm{HCl}$ followed by deionized (DI) water until the solution became almost acid-free.

\section{Preparation of GO/ZIF-8}

The nanocomposite was prepared in a sequential step-bystep process, consisting of the following steps; $1 \mathrm{~g}$ graphene oxide (as a basic layer) was dispersed in zinc sulfate $(100 \mathrm{mmol})$ solution under ultrasonic treatment for $20 \mathrm{~min}$. The suspension was centrifuged at $4500 \mathrm{rpm}$ and $40{ }^{\circ} \mathrm{C}$ and washed with water. Subsequently 2 -methyl-imidazole (100 mmol) was added to the re-dispersed GO nanoparticle suspension to form ZIF-8 coating layer on the surface of GO, and the suspension was also ultrasonically treated or $5 \mathrm{~min}$. The suspension was centrifuged at $4500 \mathrm{rpm}$ and washed as before (Fig. 2). This cycle was repeated for ten consecutive times to obtain the ZIF-8/GO nanocomposite. The obtained nanocomposite was dried by slowly adding liquid azote and putting it in a freeze drier for 2 days.

\section{ZIF-8/GO calcination}

The prepared powder was carbonized up to $800{ }^{\circ} \mathrm{C}$ under argon controlled atmosphere at $5^{\circ} \mathrm{C} / \mathrm{min}$ heat rate for $1 \mathrm{~h}$ at maximum temperature.

\section{Electrode preparation}

The pair of CDI electrodes was fabricated by mixing the ZIF-8/G nanocomposite and polyvinyl alcohol as a binder and their weight percentage were $70 \%$ and $30 \%$, respectively. Mixing was continued to be in gummy form and was coated onto a thin carbon electrode sheet then dried at $50{ }^{\circ} \mathrm{C}$ on a heater. The pair of CDI electrodes was obtained approximately with a $0.40 \mathrm{~mm}$ thickness. The pair of electrodes was used as the CDI unit cell electrodes (Fig. 3).

Fifty-milliliter $\mathrm{NaCl}$ aqueous solution, with an initial concentration of $30 \mathrm{ppm}$ and flow rate $4.5 \mathrm{ml} / \mathrm{min}$, was supplied to the cell.

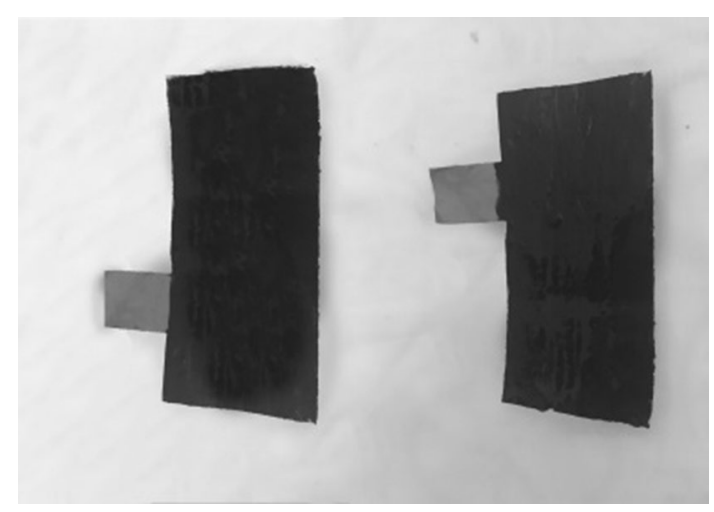

Fig. 3 A pair of electrodes ready for CDI cell

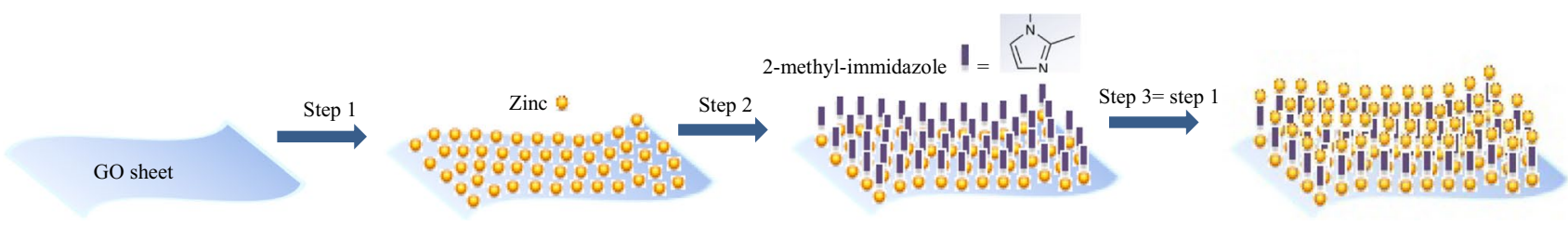

Fig. 2 Three steps of making layers of ZIF-8 on the graphene oxide surface 


\section{Characterization}

The morphology of nanomaterial was observed by a scanning electron microscope (VEGAIITESCAN). The crystallinity was checked by X'Pert PRO MPD, PANalytical Co. over a $2 \theta$ range of angles from $0^{\circ}$ to $50^{\circ}$. Thermogravimetric analyses (TGA) were carried out on TGA/ DSC 1 (METTLER TOLEDO Co., Switzerland) from 0 to $1100{ }^{\circ} \mathrm{C}$ at a heating rate of $5{ }^{\circ} \mathrm{C} / \mathrm{min}$ and under Nitrogen flow. FTIR spectra of the samples were examined using a Spectrum RX 1. Fourier Transform Infrared (FTIR) (PerkinElmer Co., USA) in the range of $500-4000 \mathrm{~cm}^{-1}$ at an average of 32 scans with a resolution of $4 \mathrm{~cm}^{-1}$. Electrical conductivity was measured by a chemical multi-function device (WA-2017SD). The electrochemical performance of the electrodes was identified by cyclic voltammetry (CV) autolab Metrohm device, at four scan rates $5,20,50,100 \mathrm{mV} / \mathrm{s}$ and voltage range -1 to 1 .

\section{Results and discussions}

\section{Electrochemical of the prepared electrodes}

\section{Electric conductivity (EC)}

Using a continuous recycling system including a CDI unit cell, a peristaltic pump, a solar power supply and a conductivity monitor, electrosorptive removal of $\mathrm{NaCl}$ of saltwater was measured. In the first experiment, a 30-ppm $\mathrm{NaCl}$ solution with the volume of $50-\mathrm{ml}$ fresh water was driven by a constant peristaltic pump, which had a flow rate of $4.5 \mathrm{ml} /$ $\min$ as feed aqueous solution to stabilize the condition. For the main experiment in the same condition, $100-\mathrm{ml}$ solution entered into the system and then $1.2 \mathrm{~V}$ potentials was applied to the CDI unit. The variation of solution conductivity was monitored instantly by a multi-function conductivity meter. Accordingly, the correlation of conductivity $(\mu \mathrm{S} / \mathrm{cm})$ was calibrated prior to the experiment. As Fig. 4 shows, the whole cycle (including the charge and discharge half cycles) lasts about an hour and a half. Each charge and discharge takes approximately $45 \mathrm{~min}$. After a vibration at the charge

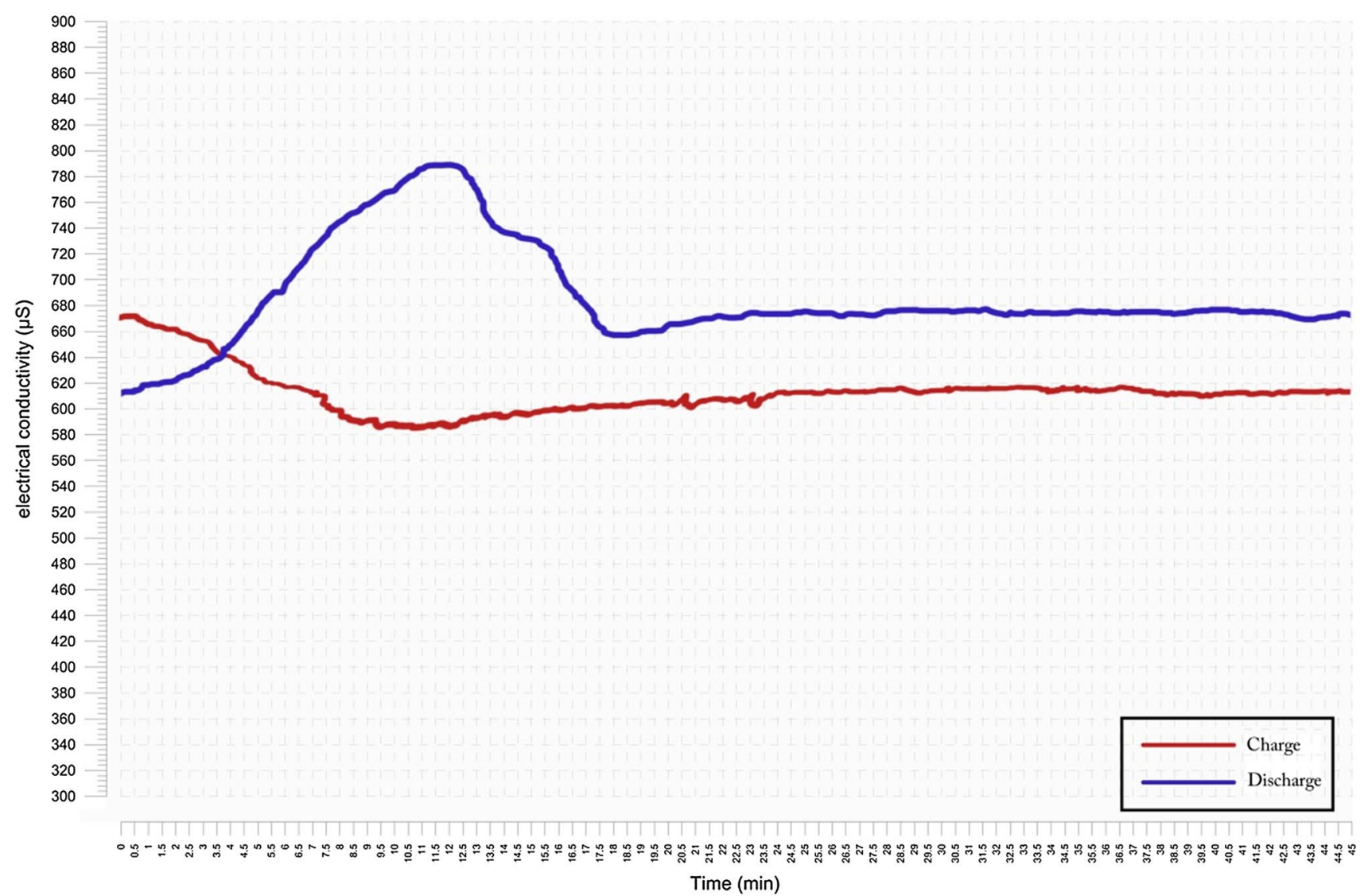

Fig. 4 Electric conductivity (EC) behavior of ZIF-8/G for a cycle containing charge and discharge for $45 \mathrm{~min}$ 
time, it stables at $610 \mu \mathrm{S} / \mathrm{cm}$ and at the discharge period, it stables at $672 \mu \mathrm{S} / \mathrm{cm}$ where the electrode regains its capacity and is ready to the next charge period and next cycle.

\section{Cyclic voltammetry (CV)}

$\mathrm{CV}$ measurements are here to evaluate the CDI performance and calculate the capacitive properties of the electrodes for adsorption/desorption capacities. The specific capacity is related to some other factors and can be estimated by the full $\mathrm{CV}$ cycle to determine the average value according to the following capacity relationship $C=\frac{\int I \mathrm{~d} V}{2 v m}$, where $C$ is the specific capacitance $(\mathrm{F} / \mathrm{g}), I$ is the response current $(\mathrm{A}), V$ is the potential $(\mathrm{V}), \nu$ is the potential scan rate $(\mathrm{V} / \mathrm{s})$, and $m$ is the mass of the electro-active materials in the electrode $(\mathrm{g})$.

The electrosorption performance of the ZIF-8/G composite electrodes was investigated based on the experimental data. It is proved that the $\mathrm{CV}$ curves have usually the shape of a rectangle, and also are presented in a full reversing cycle of charge-discharge process. At high scan rate, Faradic reactions or the inherent resistivity of the salt solutions can lead the CV curves to change to an oval shape as a result. Even a minimal scan rate is worthy for the electrosorption capacitance to gain extra access to the surface of the electrode.

In this study, the measurements were performed in a two parallel electrode electrochemical cell at room temperature using $1 \mathrm{M}$ of $\mathrm{NaCl}$ solutions, the sweep potential range was arranged $\Delta V=1$. Figure 5 displays $C V$ specific capacitance plot of ZIF-8/G composite for the prepared electrodes at different scan rates of 5, 20, 50, and $100 \mathrm{mV} / \mathrm{s}$. The specific capacitances are detected to be $141.6037 \mathrm{~F} / \mathrm{g}, 81.1438 \mathrm{~F} / \mathrm{g}$, $65.6089 \mathrm{~F} / \mathrm{g}$, and $46.1983 \mathrm{~F} / \mathrm{g}$, respectively.

\section{Morphology and crystal structure}

Preparation of nanocomposite should be verified by some structural examinations. These tests are the fingerprint of known materials. Comparing the results with the existing data leads to the certainty of well placing of ZIF-8 nanoparticles among graphene oxide sheets in order to have acceptable absorption of a noticeable amount of $\mathrm{NaCl}$ salt on the surface of the electrodes. Here are the most essential examinations. Figure 6 shows the SEM image which clearly shows a reasonable and uniform distribution of ZIF-8 particles on the graphene oxide sheet compared to the SEM image of GO. Full energy dispersive X-ray spectroscopy was used for analyzing the chemical composition of the achieved GO/ZIF-8 nanocomposite. Figure 7 indicates the X-ray diffraction to detect crystalline materials' structure and examines the characterization of solid-state chemistry as the best characterization tool. The XRD pattern of the GO/ZIF-8 nanocomposite reveals peaks of both graphene oxide and ZIF-8. We also can notice the lack of graphite crystallinity and transformation to a hydrophilic structure, so it includes GO, ZIF-8, and a variety of functional oxygenated groups such as epoxy, hydroxyl, and carboxyl.
Fig. $5 \mathrm{CV}$ carves of G/ZIF-8 at given scan rates

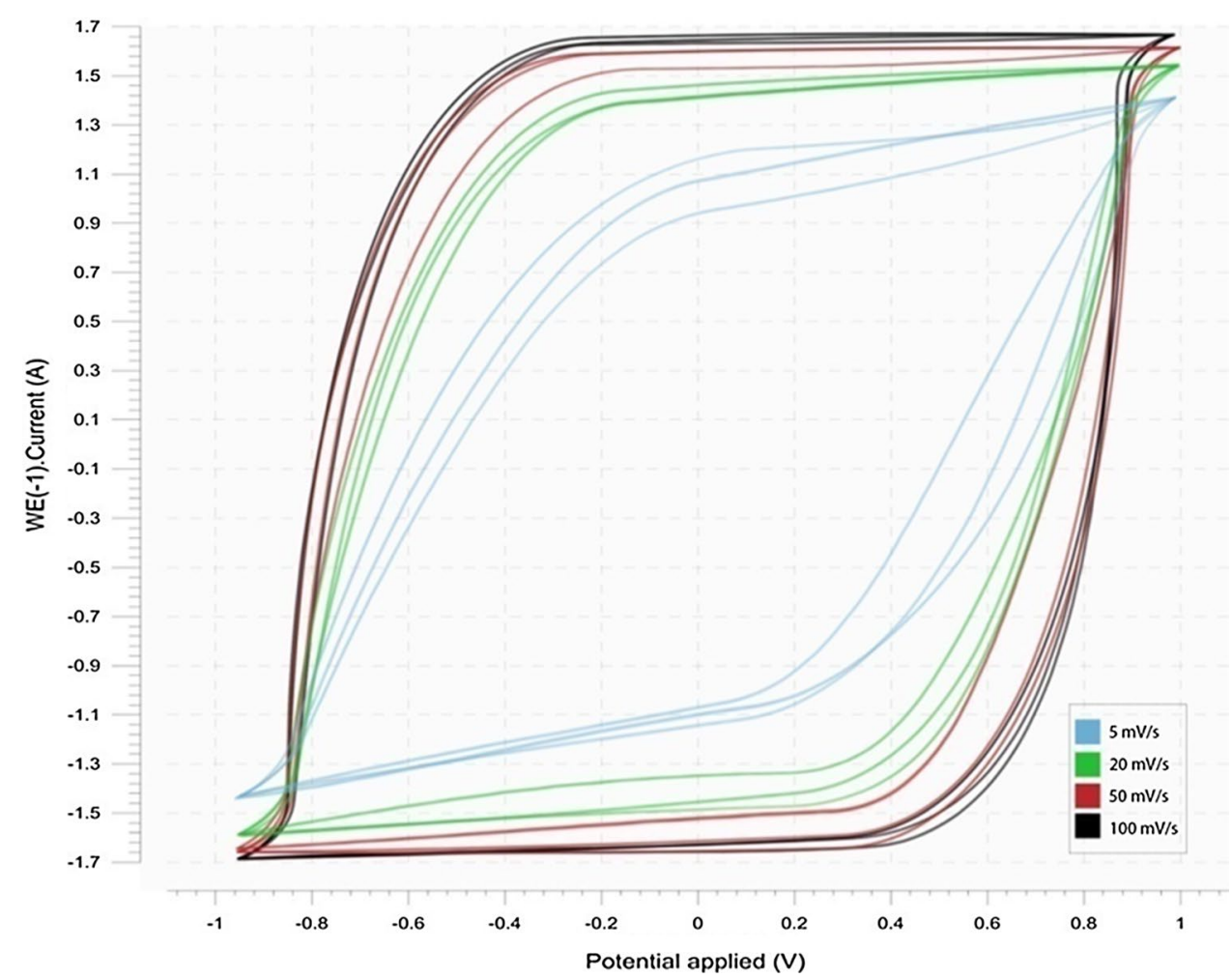

Potential applied (V) 
Fig. 6 SEM images of (a) Graphene oxide (b) GO/Zif-8 before calcination (a)

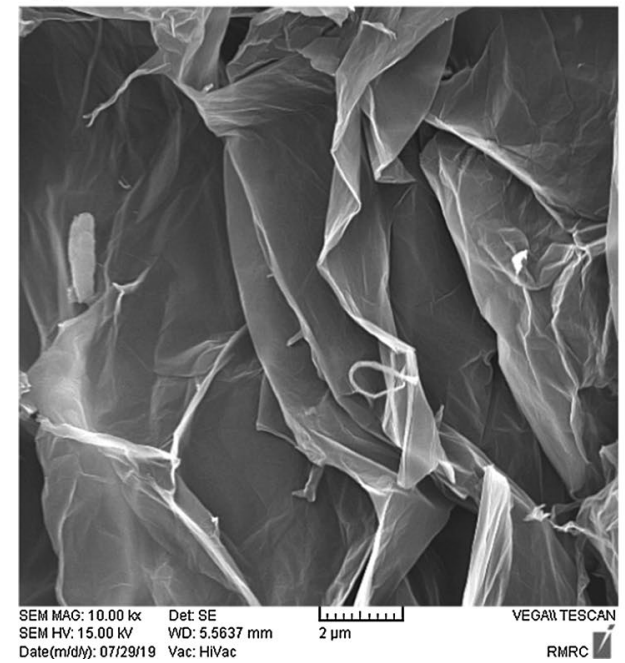

(b)

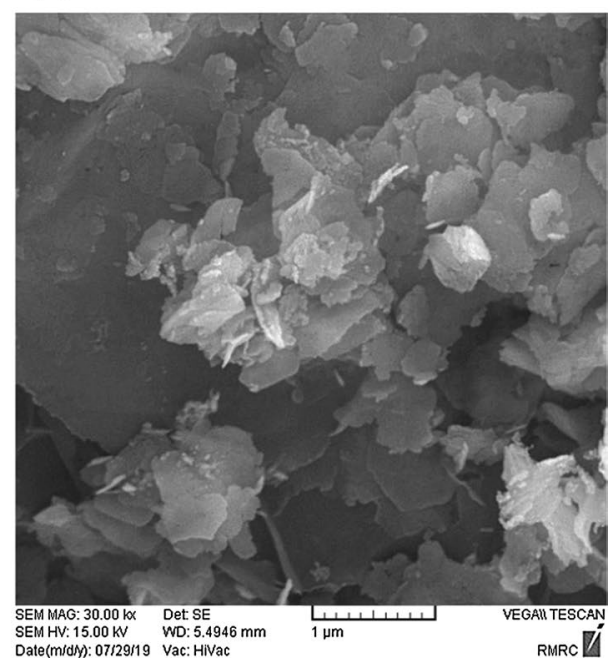

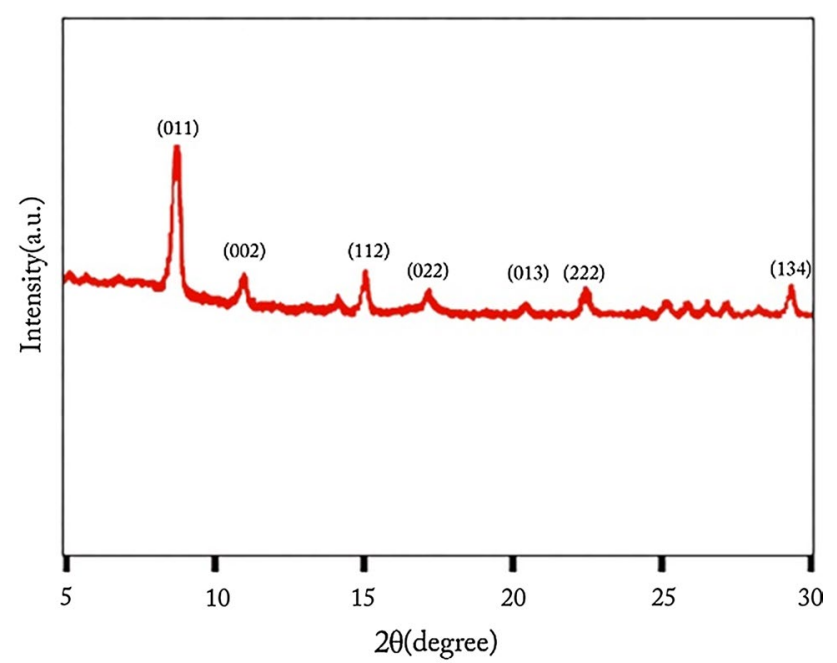

Fig. 7 XRD pattern of GO/ZIF-8

As shown, the diffraction peaks of $2 \theta ; 7.2^{\circ}, 11.2^{\circ}$, $15.2^{\circ}, 16.8^{\circ}, 20.1^{\circ}, 22.5^{\circ}$, and $29.4^{\circ}$ corresponds to (011), (002), (112), (022), (013), (222) and (134) crystal planes, respectively. Fourier Transform Infrared Spectroscopy, also known as FTIR Analysis or FTIR Spectroscopy, is an analytical technique used to identify organic, polymeric, and, in some cases inorganic materials. Figure 8 depicts the FTIR spectra of GO/ZIF-8. The peaks of GO attributed to $-\mathrm{OH}$ stretching vibrations can be seen at $3421 \mathrm{~cm}^{-1}$. Also, peaks of $\mathrm{C}=\mathrm{O}$ stretching vibration are seen at approximately $1717 \mathrm{~cm}^{-1}$, of $\mathrm{C}=\mathrm{C}$ from unoxidized sp2 bonds in the range of $1452-1627 \mathrm{~cm}^{-1}$, and of $\mathrm{C}-\mathrm{O}$ vibrations at $1322 \mathrm{~cm}^{-1}$. The peak at $2724 \mathrm{~cm}^{-1}$ is attributed to enols, phenols, alcohols, and $\mathrm{CO}-\mathrm{OH}$ taking parts in hydrogen connections. The $2345 \mathrm{~cm}^{-1}$ band attributed to asymmetric stretching vibrations $\mathrm{CO}_{2}$. The infrared spectrum of ZIF-8

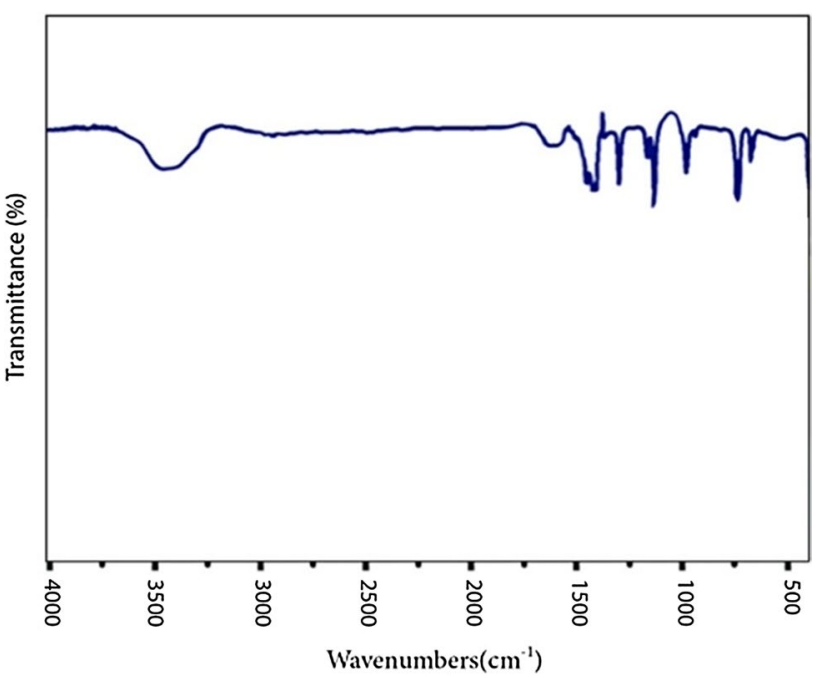

Fig. 8 FTIR spectra of GO/ZIF-8

shows peaks at $1584,2929,3482 \mathrm{~cm}^{-1}$, and at the range of 528 up to $1472 \mathrm{~cm}^{-1}$, respectively, attributes to aromatic and aliphatic $\mathrm{C}-\mathrm{H}, \mathrm{C}=\mathrm{H}$, and $\mathrm{Zn}-\mathrm{N}$. Thermogravimetric analysis or thermal gravimetric analysis (TGA) is a method of thermal analysis in which the mass of a sample is measured over time as the temperature changes. Figure 9 illustrates the TGA of GO/ZIF-8. At first, there is a decline in the diagram which indicates the existence of moisture or impurity in the material that as it goes by increasing the temperature it loses its weight. There is another loss before $500{ }^{\circ} \mathrm{C}$ which is attributed to the decomposition of oxygencontaining functional groups. The final declination occurred around $710{ }^{\circ} \mathrm{C}$ which is due to the formation of graphitic framework and the release of nitrogen-containing gases. At $800{ }^{\circ} \mathrm{C}$, fully converts from the amorphous carbon framework to graphitic framework. So, this temperature has been 
Fig. 9 TGA profiles of GO/ ZIF-8

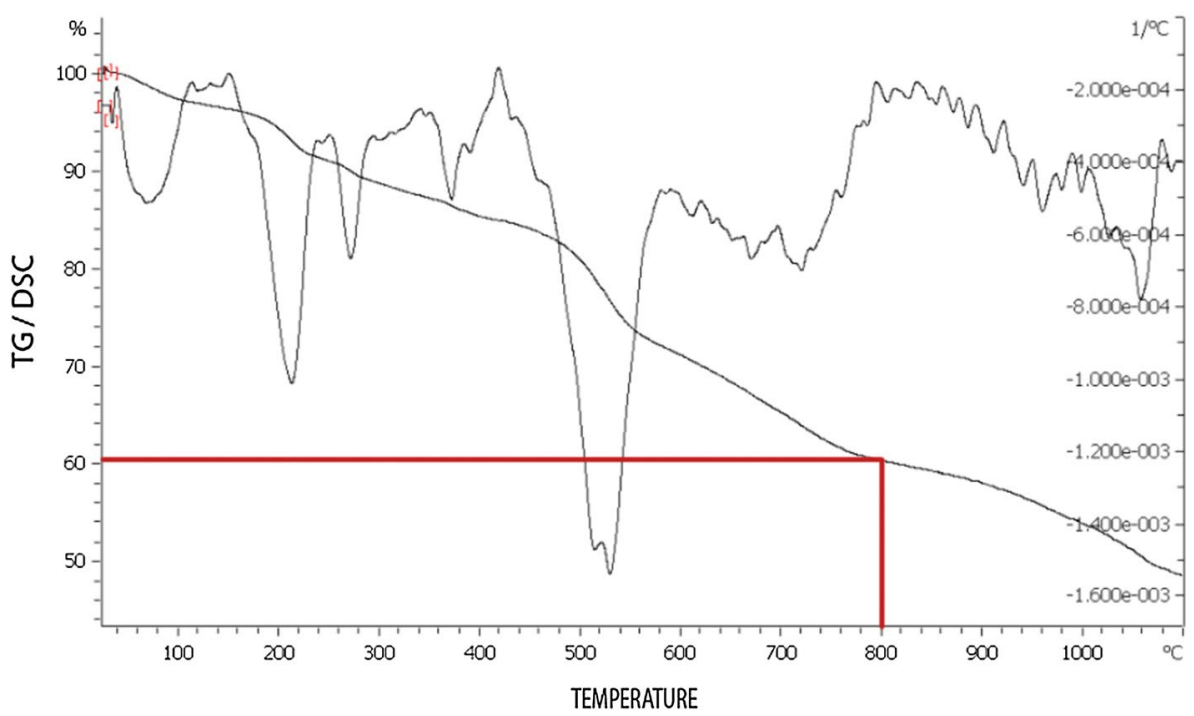

chosen. In addition, it could be considered that almost $42 \%$ of synthesized nanomaterial is left. Therefore, in order to have about $3 \mathrm{~g}$ of the calcinated nanocomposite, there must be about $7 \mathrm{~g}$ of it before calcination.

\section{Conclusions}

In the present work, ZIF-8/G hybrid adsorbents were synthesized, carbonized at $800{ }^{\circ} \mathrm{C}$ under Ar atmosphere, and the effect of functionalization on $\mathrm{NaCl}$ adsorption was investigated. The morphology, crystal structure, Fourier Transform Infrared Spectroscopy, and the thermal gravimetric analysis were investigated, and they verified that ZIF-8 particles were well sited on 3D graphene sheet and then caused a significant specific capacity compared to unmodified electrodes which were proved by electrochemical performances measurements. In CDI experiments, it exhibits a well-defined mesoporous structure with a high electrical conductivity of $672 \mu$ s. The specific capacitance of ZIF-8/G nanocomposite demonstrated a high value of $141.6037 \mathrm{~F} / \mathrm{g}$ at $5 \mathrm{mV} / \mathrm{s} \mathrm{scan}$ rate which shows more capacity than the same work with $950{ }^{\circ} \mathrm{C}$ calcination in similar study (Stoller et al. 2008). The cell voltage was fixed at $1.2 \mathrm{~V}$ that shows its low energy consumption. Thus, the performance of ZIF-8/G nanocomposite electrode prepared in this study indicates that it is a desirable material for the removal of ions in CDI.

Funding The author(s) received no specific funding for this work.

\section{Compliance with ethical standards}

Conflict of interests There is no conflict of interest on this manuscript.
Open Access This article is licensed under a Creative Commons Attribution 4.0 International License, which permits use, sharing, adaptation, distribution and reproduction in any medium or format, as long as you give appropriate credit to the original author(s) and the source, provide a link to the Creative Commons licence, and indicate if changes were made. The images or other third party material in this article are included in the article's Creative Commons licence, unless indicated otherwise in a credit line to the material. If material is not included in the article's Creative Commons licence and your intended use is not permitted by statutory regulation or exceeds the permitted use, you will need to obtain permission directly from the copyright holder. To view a copy of this licence, visit http://creativecommons.org/licenses/by/4.0/.

\section{References}

AlMarzooqi FA et al (2014) Application of capacitive deionisation in water desalination: a review. Desalination 342:3-15

Al-Shammiri M, Safar MJD (1999) Multi-effect distillation plants: state of the art. Desalination 126(1-3):45-59

Cohen I, Avraham E, Noked M, Soffer A, Aurbach D (2011) Enhanced charge efficiency in capacitive deionization achieved by surface-treated electrodes and by means of a third electrode. J Phys Chem C 115:19856-19863

Duan X, Liu W, Chang L (2016) Porous carbon prepared by using ZIF-8 as precursor for capacitive deionization. J Taiwan Inst Chem Eng 62:132-139

Elimelech M, Phillip WA (2011) The future of seawater desalination: energy, technology, and the environment. Science 333(6043):712-717

El-Sayed YMJD (1996) On the feasibility of large vapor-compression distillation units. Desalination 107(1):13-27

Farmer JC et al (1996) Capacitive deionization of $\mathrm{NaCl}$ and $\mathrm{NaNO}_{3}$ solutions with carbon aerogel electrodes. J Electrochem Soc 143(1):159-169

Gao X, Omosebi A, Landon J, Liu K (2015) Surface charge enhanced carbon electrodes for stable and efficient capacitive deionization using inverted adsorption-desorption behavior. Energy Environ Sci 8:897-909

Gao X, Omosebi A, Landon J, Liu K (2018) Voltage-based stabilization of microporous carbon electrodes for inverted capacitive deionization. J Phys Chem C 122(2):1158-1168 
Jeon S et al (2013) Desalination via a new membrane capacitive deionization process utilizing flow-electrodes. Energy Environ Sci 6:1471-1475

Johnson AM, Newman J (1971) Desalting by means of porous carbon electrodes. J Electrochem Soc 118:510-517

Kim Y-J, Choi J-H (2010) Enhanced desalination efficiency in capacitive deionization with an ion-selective membrane. Sep Purif Technol 71(1):70-75

Kumar R et al (2013) Hybrid nanocomposites of ZIF-8 with graphene oxide exhibiting tunable morphology, significant $\mathrm{CO}_{2}$ uptake and other novel properties. Chem Commun 49(43):4947-4949

Landon J et al (2012) Impact of pore size characteristics on the electrosorption capacity of carbon xerogel electrodes for capacitive deionization. J Electrochem Soc 159(11):A1861-A1866

Lee J, Kim S, Kim C, Yoon J (2014) Hybrid capacitive deionization to enhance the desalination performance of capacitive techniques. Energy Environ Sci 7:3683-3689

Li D et al (2008) Processable aqueous dispersions of graphene nanosheets. Nat Nanotechnol 3(2):101

$\mathrm{Li} \mathrm{H}$ et al (2010a) Novel graphene-like electrodes for capacitive deionization. Environ Sci Technol 44(22):8692-8697

$\mathrm{Li} \mathrm{H}$ et al (2010b) Kinetics and thermodynamics study for electrosorption of $\mathrm{NaCl}$ onto carbon nanotubes and carbon nanofibers electrodes. Chem Phys Lett 485(1-3):161-166

Li C et al (2014) Decoration of graphene network with metal-organic frameworks for enhanced electrochemical capacitive behavior. Carbon 78:231-242

Mirzadeh M, Gibou F, Squires TM (2014) Enhanced charging kinetics of porous electrodes: surface conduction as a short-circuit mechanism. Phys Rev Lett 113:97701

Ordonez MJC et al (2010) Molecular sieving realized with ZIF-8/Matrimid ${ }^{\circledR}$ mixed-matrix membranes. J Membr Sci 361(1-2):28-37

Park K-K et al (2007) Development of a carbon sheet electrode for electrosorption desalination. Desalination 206(1-3):86-91

Pendergast MM, Hoek EMJE (2011) A review of water treatment membrane nanotechnologies. Energy Environ Sci 4(6):1946-1971

Pilat BJD (2001) Practice of water desalination by electrodialysis. Desalination 139(1-3):385-392

Pokhrel J et al (2018) $\mathrm{CO}_{2}$ adsorption behavior of amine-functionalized ZIF-8, graphene oxide, and ZIF-8/graphene oxide composites under dry and wet conditions. Microporous Mesoporous Mater 267:53-67

Porada $\mathrm{S}$ et al (2012) Water desalination using capacitive deionization with microporous carbon electrodes. ACS Appl Mater Interfaces 4(3):1194-1199

Porada S et al (2013) Review on the science and technology of water desalination by capacitive deionization. Prog Mater Sci 58(8):1388-1442
Presser V, Heon M, Gogotsi YJ (2011) Carbide-derived carbons-from porous networks to nanotubes and graphene. Adv Funct Mater 21(5):810-833

Rica RA, Ziano R, Salerno D, Mantegazza F, Brogioli D (2012) Thermodynamic relation between voltage-concentration dependence and salt adsorption in electrochemical cells. Phys Rev Lett 109:156103

Srimuk P et al (2016) MXene as a novel intercalation-type pseudocapacitive cathode and anode for capacitive deionization. J Mater Chem A 4:18265-18271

Stoller MD et al (2008) Graphene-based ultracapacitors. Nano Lett 8(10):3498-3502

Suss ME et al (2012) Capacitive desalination with flow-through electrodes. Energy Environ Sci 5:9511-9519

Tanaka H, Nosoko T, Nagata TJD (2000) Parametric investigation of a basin-type-multiple-effect coupled solar still. Desalination 130(3):295-304

Wang S et al (2007) Equilibrium and kinetic studies on the removal of $\mathrm{NaCl}$ from aqueous solutions by electrosorption on carbon nanotube electrodes. Sep Purif Technol 58(1):12-16

Wang G et al (2012) Hierarchical activated carbon nanofiber webs with tuned structure fabricated by electrospinning for capacitive deionization. J Mater Chem 22(41):21819-21823

Wang M et al (2017) High performance capacitive deionization electrodes based on ultrathin nitrogen-doped carbon/graphene nanosandwiches. Chem Commun 53(78):10784-10787

Yang J, Zhao F, Zeng BJ (2015) One-step synthesis of a copperbased metal-organic framework-graphene nanocomposite with enhanced electrocatalytic activity. RSC Adv 5(28):22060-22065

Yasin AS et al (2016) Enhanced desalination performance of capacitive deionization using zirconium oxide nanoparticles-doped graphene oxide as a novel and effective electrode. Sep Purif Technol 171:34-43

Zhai Y et al (2011) Carbon materials for chemical capacitive energy storage. Adv Energy Mater 23(42):4828-4850

Zhou $\mathrm{H}$ et al (2015) High-capacity room-temperature hydrogen storage of zeolitic imidazolate framework/graphene oxide promoted by platinum metal catalyst. Int J Hydrog Energy 40(36):12275-12285

Zou L et al (2008) Using mesoporous carbon electrodes for brackish water desalination. Water Res 42(8-9):2340-2348

Publisher's note Springer Nature remains neutral with regard to jurisdictional claims in published 44maps and institutional affiliations. 